\title{
Reduced Expression of Fibroblast Growth Factor Receptor 2lllb in Hepatocellular Carcinoma Induces a More Aggressive Growth
}

Thomas Amann, ${ }^{*}$ Frauke Bataille, ${ }^{\dagger}$ Thilo Spruss, ${ }^{\neq}$ Katja Dettmer, $\$$ Peter Wild, " Christian Liedtke," Marcus Mühlbauer, ${ }^{*}$ Paul Kiefer, ${ }^{* *}$

Peter J. Oefner, ${ }^{\S}$ Christian Trautwein," Anja-Katrin Bosserhoff, ${ }^{\dagger}$ and Claus Hellerbrand*

From the Department of Internal Medicine I, ${ }^{*}$ and Institutes of Pathology, ${ }^{\dagger}$ Pharmacy, ${ }^{\ddagger}$ Functional Genomics, ${ }^{\S}$ and Clinical Chemistry,*: University of Regensburg, Regensburg, Germany; the Institute of Surgical Pathology, "Tniversity Hospital Zurich, Zurich, Switzerland; and the Department of Internal Medicine III," University Hospital, Aachen Germany

Fibroblast growth factor receptor 2 isoform b (FGFR2IIIb) is highly expressed in hepatocytes and plays an important role in liver homeostasis and regeneration. Here, we analyzed the expression and function of FGFR2-IIIb in hepatocellular carcinoma (HCC). FGFR2IIIb expression in HCC tissues and cell lines was lower than in primary human hepatocytes and nontumorous tissue. FGFR2-IIIb-negative HCCs showed a significantly higher Ki-67 labeling index, and loss of FGFR2-IIIb expression correlated significantly with vascular invasion and more advanced tumor stages. A decrease in FGFR2IIIb expression in HCC cell lines was not related to promoter hypermethylation. However, PCR analysis indicated that chromosomal deletion at 10q accounted for the loss of FGFR2 expression in a subset of HCC cells. FGFR2-IIIb re-expression in stable transfected HCC cell lines induced a higher basal apoptosis rate and a significantly reduced proliferation and migratory potential in vitro. In nude mice, FGFR2-IIIb re-expressing HCC cells grew significantly slower, and terminal deoxynucleotidyl transferase-mediated dUTP nick-end labeling assay revealed higher apoptosis rates. The antitumorigenic effects of FGFR2-IIIb expression in HCC cells were not affected by keratinocyte growth factor or an inhibitor of FGFR-phosphorylation, indicating that they are independent of tyrosine kinase activation. In conclusion, our data indicate that FGFR2-IIIb inhibits tumorigenicity of HCC cells. Identification of the molecular mechanisms promoting regeneration in normal tissue while suppressing malignancy may lead to novel therapeutic targets of this highly aggressive tumor. (Am J Pathol 2010, 176:1433-1442; DOI: 10.2353/ajpath.2010.090356)

Fibroblast growth factor receptors (FGFRs) are transmembrane tyrosine kinase receptors. They are involved in signal transduction processes that regulate cell growth, differentiation, migration, wound healing, and angiogenesis, depending on target cell type and developmental stage. They are encoded by four different genes, FGFR1-4, and among the 23 different fibroblast growth factor genes identified, 18 have been shown to encode FGFR ligands. ${ }^{1}$

FGFRs are glycoproteins with an extracellular domain composed of two or three Ig-like domains, which mediate ligand binding and interaction with heparan sulfate proteoglycans, a hydrophobic transmembrane region and an intracellular region containing a juxtamembrane domain, a tyrosine kinase catalytic domain, and a carboxyterminal domain with multiple tyrosine phosphorylation sites. The diversity of the FGFR family is increased by alternative mRNA splicing. In humans, the second half of the third Ig-like domain of FGFR1-3 is encoded by either exon IIIb or IIIc, generating receptors with different ligand-binding specificities and affinities. ${ }^{2,3}$

FGFR2-IIIb, the isoform containing the second half of the third Ig-like domain (also called FGFR2b, keratinocyte growth factor receptor [KGFR], or Ksam-IIC1), binds FGF1, FGF3, FGF7/Keratinocyte growth factor (KGF), FGF10, and FGF22 with high affinity. In contrast, FGFR2-IIIc, the isoform containing the second half of the third Ig-like domain (FGFR2-IIIc/Bek), binds

Supported by grants from the German Research Association to P.K. A.-K.B., and C.H., the Medical Faculty of the University of Regensburg (ReForM) to P.J.O., A.-K.B., and C.H., and BayGene to P.J.O., C.L. and C.T. are supported by the German Research Association.

Accepted for publication November 10, 2009.

Address reprint requests to Claus Hellerbrand, M.D., University of Regensburg, Department of Internal Medicine I, D-93042 Regensburg, Germany. E-mail: claus.hellerbrand@klinik.uni-regensburg.de. 
FGF1 and FGF2 but not FGF7/KGF, FGF10, or FGF22. ${ }^{4}$ FGFR2-IIIb expression is mainly restricted to epithelial cells, whereas FGFR2-IIIc is located primarily in the mesenchyme. ${ }^{2}$

In several cases, FGFRs have been implicated as oncogenes in tumorigenesis. Translocations involving the kinase domain of FGFR1 have been demonstrated in hematopoietic malignancies, ${ }^{5}$ and the activation of FGFR3 by point mutations is a frequent event in bladder cancer. ${ }^{6}$ FGFR1 overexpression has been identified in a wide variety of cancers. ${ }^{7}$

In contrast to this role of FGFRs as positive regulators of tumorigenesis, FGFR2 has been reported to be downregulated in several cancers, including cancer of the bladder or the prostate, suggesting that FGFR2-IIIb may also have tumor suppressor properties. ${ }^{8-10}$ Further, lossof-function mutations in the FGFR2 gene have been detected in malignant melanoma. ${ }^{11}$ However, there is evidence that in tumors of the stomach or the lung FGFR2-IIIb expression is associated with a less differentiated phenotype and a worse prognosis for the patients. ${ }^{12}$ Moreover, activating FGFR2 mutations are frequent in endometrial cancer, ${ }^{13,14}$ further suggesting that FGFR2 plays opposing roles in a cancer of different origin.

To date, the expression and function of FGFR2-IIIb in hepatocellular carcinoma (HCC) have not been analyzed. Primary HCC is the fifth most frequent cancer and the third most common cause of cancer-related deaths in the world with an increasing incidence in Western countries. ${ }^{15}$ Histopathological and molecular findings suggest that HCC develops through a multistep process with accumulating genetic alterations. However, the molecular pathogenesis of HCC is still not well understood. While novel therapeutic strategies have significantly improved the survival of patients with tumors detected at early stages, the majority of patients are still given a diagnosis at an advanced stage, and their prognosis remains poor. ${ }^{16-18}$ The presence of liver cirrhosis is the main risk factor for the development of HCC. Activated hepatic stellate cells are the effector cells of hepatic fibrosis. After hepatic injury, hepatic stellate cells undergo an activation process and transform to an activated, myofibroblast-like phenotype. They are responsible for the excessive hepatic matrix deposition, and their activation is recognized as a central event in the development of hepatic fibrosis and lastly, cirrhosis. ${ }^{19,20}$

Previously, we have shown that in the liver FGFR2-IIIb is exclusively expressed on hepatocytes, while the ligand FGF7/KGF is de novo expressed by activated hepatic stellate cells during liver fibrosis. ${ }^{21}$ Further, we found that FGFR2-IIIb plays a critical role in liver regeneration and homeostasis. ${ }^{22}$

Here, we show that FGFR2-IIlb expression is downregulated or lost in most $\mathrm{HCC}$ cell lines and tissues, and we provide evidence that reduced FGFR2-IIIb expression in HCC induces a more aggressive growth of HCC cells in vitro and in vivo.

\section{Materials and Methods}

\section{Cells and Cell Culture}

The HCC cell lines HepG2 (American Type Culture Collection, number HB-8065; Manassas, Virginia), PLC (American Type Culture Collection, number CRL-8024), and HuH-7 (Japan Collection of Research Bioresources (JCR) B0403) were cultured as described previously. ${ }^{23}$ FGFR2-IIIb expressing cell clones were established by stable transfection of HepG2 cells with a FGFR2-IIIb expression plasmid ${ }^{24}$ (kindly provided by Professor Sabine Werner, Zurich, Switzerland). To induce apoptosis in HCC cells, a recently described model of lipoapoptosis was applied. ${ }^{25}$ Here, cells were incubated in serum-free Dulbecco's modified Eagle's medium supplemented with $0.1 \mathrm{mmol} / \mathrm{L}$ palmitate $/ 0.4 \%$ bovine serum albumin for 24 hours. Primary human hepatocytes $(\mathrm{PHH})$ were isolated and cultured as described. ${ }^{23}$

\section{Murine HCC Tissues}

For our study we used specimens obtained from two murine HCC models: transgenic mouse strains expressing either human IgEGF under the control of the liver specific albumin promoter or the murine c-myc gene under control of the $\alpha$-1-antitrypsin promoter ${ }^{26}$ For isolation of HCC and corresponding noncancerous liver tissue, the animals were sacrificed by cervical dislocation, and the liver and tumor nodes were dissected by using surgical instruments.

\section{Human Tissues and HCC Tissue Microarray}

Corresponding HCC tissues and non-neoplastic liver tissues were obtained from 15 patients with HCC undergoing surgical resection. A tissue microarray was constructed as described. ${ }^{23}$ Clinicopathological patient characteristics are summarized in Table 1. Human liver tissue was obtained from and experimental procedures were performed according to the guidelines of the charitable state controlled foundation Human Tissue and Cell Research (HTCR), with the informed patient's consent.

\section{Tumor Cell Inoculation and Measurement of Tumor Growth in NMRI (nu/nu) Mice}

A model of inoculation of tumor cells into NMRI (nu/nu) mice to monitor tumor growth in vivo was performed as described. ${ }^{23}$ Briefly, FGFR2-IIllb-expressing cell clones and control cells were harvested after incubation with PBS containing $0.05 \%$ trypsin and $0.04 \%$ ethylenediaminetetraacetic acid (Sigma-Aldrich, Steinheim, Germany). Tumor cells were washed twice with serum-free Dulbecco's modified Eagle's medium at room temperature and were resuspended in Dulbecco's modified Eagle's medium at a concentration of $1 \times 10^{7}$ cells $/ \mathrm{ml}$. For each of the cell lines, a group of $10 \mathrm{NMRI}(\mathrm{nu} / \mathrm{nu})$ mice with a mean body weight of $32 \mathrm{~g}$ was formed. All mice were injected subcutaneously with a cell suspension of $0.1 \mathrm{ml}$ 
Table 1. FGFR2-IIIb Immunoreactivity in HCC Tissue of 85 Patients in Relation to Clinicopathological Characteristics and Proliferation Rate

\begin{tabular}{|c|c|c|c|c|c|c|}
\hline \multicolumn{3}{|c|}{ Variable } & \multicolumn{3}{|c|}{ FGFR2-IIIb immunoreactivity } & \multirow[b]{2}{*}{$P^{*}$} \\
\hline Categorization & $n$ & $\%$ & Negative & Score $1+$ & Score $2+$ & \\
\hline \multicolumn{7}{|c|}{ Clinicopathological characteristics } \\
\hline \multicolumn{7}{|c|}{ Age at diagnosis, y } \\
\hline$<60$ & 39 & 45.9 & 17 & 19 & 3 & 0.337 \\
\hline$\geq 60$ & 46 & 54.1 & 13 & 28 & 5 & \\
\hline \multicolumn{7}{|l|}{ Sex } \\
\hline Female & 16 & 18.8 & 8 & 8 & 0 & 0.244 \\
\hline Male & 69 & 81.2 & 22 & 39 & 8 & \\
\hline \multicolumn{7}{|l|}{ Tumor stage } \\
\hline pT1 & 13 & 15.3 & 1 & 10 & 2 & $0.016^{\dagger}$ \\
\hline pT2 & 25 & 29.4 & 6 & 16 & 3 & \\
\hline pT3 & 41 & 48.2 & 19 & 20 & 2 & \\
\hline pT4 & 3 & 3.5 & 2 & 0 & 1 & \\
\hline ND & 3 & 3.5 & 2 & 1 & 0 & \\
\hline \multicolumn{7}{|l|}{ Vascular invasion } \\
\hline No & 33 & 38.8 & 8 & 21 & 4 & $0.030^{\dagger}$ \\
\hline Yes & 42 & 49.4 & 21 & 17 & 4 & \\
\hline ND & 10 & 11.8 & 1 & 9 & 0 & \\
\hline \multicolumn{7}{|l|}{ Histological grade } \\
\hline G1 & 29 & 34.1 & 12 & 14 & 3 & 0.487 \\
\hline G2 & 48 & 56.5 & 17 & 26 & 5 & \\
\hline G3 & 8 & 9.4 & 1 & 7 & 0 & \\
\hline \multicolumn{7}{|l|}{ Etiology } \\
\hline HBV & 9 & 10.6 & 5 & 3 & 1 & 0.744 \\
\hline $\mathrm{HCV}$ & 7 & 8.2 & 2 & 4 & 1 & \\
\hline Alcohol & 34 & 40.0 & 13 & 17 & 4 & \\
\hline Others & 3 & 3.5 & 1 & 2 & 0 & \\
\hline Unknown & 32 & 37.6 & 9 & 21 & 2 & \\
\hline \multicolumn{7}{|l|}{ Tumor size, $\mathrm{cm}$} \\
\hline$\leq 5$ & 36 & 42.4 & 14 & 19 & 3 & 0.570 \\
\hline$>5$ & 30 & 35.3 & 9 & 16 & 5 & \\
\hline ND & 19 & 22.4 & 7 & 12 & 0 & \\
\hline \multicolumn{7}{|c|}{ Proliferation rate (MiB-1 Index), \% } \\
\hline$\leq 5$ & 40 & 47.1 & 5 & 29 & 6 & $<0.0001^{\dagger}$ \\
\hline$>5$ & 45 & 52.9 & 25 & 18 & 2 & \\
\hline
\end{tabular}

ND, no data available; HBV, hepatitus B virus; HCV, hepatitus C virus.

* Fisher's exact test (two-sided).

$+P$ value $<0.05$

containing $1 \times 10^{6}$ cells of a single line. Tumor growth kinetics were recorded by weekly measurement of tumor diameters at the inoculation site (region of the thoracic mammary fat pad) with an electronic caliper. Tumor areas were calculated as the product of two perpendicular diameters, one measured across the greatest width of the tumor. For ethical reasons, mice were sacrificed at day 21 after the first tumors underwent ulceration, and the tumors were taken out and stored for subsequent analysis.

\section{Preparation of Genomic DNA and Methylation-Specific PCR Analysis}

Genomic DNA specimens were prepared as described. ${ }^{27}$ A PCR assay, adapted as described by Ricol et al, ${ }^{10}$ based on the inability of certain restriction enzymes to cut methylated DNA, was used to assess the methylation status of the $5^{\prime}$ region of the FGFR2 gene. DNA $(1 \mathrm{mg})$ was cut with 10 $\mathrm{U}$ of ATII and $10 \mathrm{U}$ of Mspl (methylation-insensitive) or EcIVI and Smal or Hpall (all methylation-sensitive) for 16 hours at $37^{\circ} \mathrm{C}\left(25^{\circ} \mathrm{C}\right.$ for Smal). Restriction enzymes were then heatinactivated. Digested DNA (50 ng) was amplified with prim- ers corresponding to sequences flanking the described $\mathrm{CpG}$ island within the promoter of the FGFR2 gene (forward: 5'-AGTCACTCA GCGAGCCGTTGG-3'; reverse: 5'-GGGTCACGCCCCCACTGAAAC- $\left.3^{\prime}\right) .{ }^{10}$

For a rough analysis of genomic deletions, a $344 \mathrm{bp}$ fragment of the FGFR2 gene containing exon 8 was amplified by using a pair of primers previously published (FGFR2-forward: 5'-GCCGCTGTTTAGACGTAATG-3';

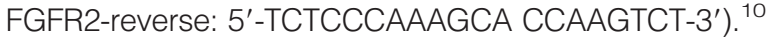

PCR products were separated by electrophoresis in a $2 \%$ agarose gel and were visualized by ethidium bromide staining. PCR for genomic B-actin was used as a control. ${ }^{23}$

\section{Expression Analysis}

Isolation of total cellular RNA from cultured cells and tissues and reverse transcription were performed as described previously. ${ }^{23}$ Quantitative real time-PCR was performed with specific sets of primers (Table 2) applying LightCycler technology (Roche, Mannheim, Germany) as described. ${ }^{23}$ 
Table 2. Sets of Primers Used for Quantitative PCR Analysis

\begin{tabular}{|c|c|c|}
\hline Gene & Forward primer & Reverse primer \\
\hline \multicolumn{3}{|l|}{ Human } \\
\hline$\beta$-Actin & 5'-CTACGTCGCCCTGGACTTCGAGC-3' & 5'-GATGGAGCCGCCGATCCACACGG-3' \\
\hline FGFR2-IIIb & $5^{\prime}-$ TGCTGGCTCTGTTCAATGTG-3' & $5^{\prime}$-GGCGATTAAGAAGACCCCTA-3' \\
\hline FGFR2-IIIC & $5^{\prime}-$ ACACCACGGACAAAGAGATT- $3^{\prime}$ & 5'-GGCGATTAAGAAGACCCCTA-3' \\
\hline \multicolumn{3}{|l|}{ Mouse } \\
\hline$\beta$-Actin & $5^{\prime}$-AGGCCAACCGTGAAAAGAT-3' & 5'-GGCGTGAGGGAGAGCATA-3' \\
\hline FGFR2-IIIb & $5^{\prime}-$ GCCCATCCTCCAAGCTG-3' & 5'-TGGTTGGCCTGCCCTATA-3' \\
\hline
\end{tabular}

\section{Protein Analysis}

Polyclonal antibodies against FGFR2-IIIb were prepared by immunization of rabbits against synthetic peptides in cooperation with Biogenes (Berlin, Germany). To generate the anti-FGFR2-IIIb antibody, we selected a synthetic oligopeptide sequence, HSGINSSNAEVL, corresponding to the part of alternative spliced variant IIIb (Nos 314325), which is located in the extracellular third IgG domain of human FGFR2-IIIb. ${ }^{3}$

Protein extraction, Western blotting, and immunohistochemistry were performed as described ${ }^{23,27}$ by using the antiserum at a dilution of 1:400. Immunohistochemical staining intensity was estimated by using a semiquantitative three-step scoring system as described. MIB1 was analyzed by applying Ki-67 antibody. ${ }^{23}$

\section{Analysis of ${ }^{2} \mathrm{H}_{8}$-Valine Protein Incorporation}

Overall, protein synthesis was analyzed by determining $\left[{ }^{2} \mathrm{H}_{8}\right]$-valine protein incorporation similarly as previously described. ${ }^{28}$ Briefly, cells were lysed in $100 \mu \mathrm{l}$ of radioimmunoprecipitation assay buffer followed by the addition of $1 \mathrm{ml}$ of cold ethanol to precipitate proteins. Samples were vortexed and then centrifuged at $4{ }^{\circ} \mathrm{C}$ and $2220 \times g$ for 8 minutes. The supernatant containing free intracellular $\left[{ }^{2} \mathrm{H}_{8}\right]$-valine was discarded while the protein pellet was resuspended in $200 \mu \mathrm{l}$ of water and transferred into a 2-ml glass vial. The water was removed (CombiDancer, Hettich AG, Bäch, Switzerland), $100 \mu$ l of $6 \mathrm{~N} \mathrm{HCL}$ was added to the residue, and vials were closed gas-tight with crimp caps. Protein hydrolysis was performed at $110^{\circ} \mathrm{C}$ over night. After the samples were cooled to room temperature, the vials were opened and $600 \mu$ of $1 \mathrm{~N} \mathrm{NaOH}$ solution were added to neutralize the hydrolyzed samples. The samples were evaporated to complete dryness and then reconstituted in $185 \mu \mathrm{l}$ of water for quantitative gas chromatography-mass spectrometry (GC-MS) analysis of $\left[{ }^{2} \mathrm{H}_{8}\right]$-valine. Analysis was performed after derivatization with propyl chloroformate as described. ${ }^{29}$

Before analysis, $20 \mu$ l of stabilization reagent containing 10\% n-propanol, 0.1\% phenol, and 2\% thiodiglycol, and the internal standards norvaline and a mixture of uniformly ${ }^{13} \mathrm{C},{ }^{15} \mathrm{~N}$-labeled amino acids including valine were added to the sample. The mass spectrometry (MS) was operated in selected ion monitoring mode by using $\mathrm{m} / \mathrm{z} 158,163$, and 166 as quantifier ions for valine, $\mathrm{U}-{ }^{13} \mathrm{C},{ }^{15} \mathrm{~N}$-valine and $\left[{ }^{2} \mathrm{H}_{8}\right]$-valine. $\mathrm{U}-{ }^{13} \mathrm{C},{ }^{15} \mathrm{~N}$ valine was used as internal standard to normalize peak areas of $\left[{ }^{2} \mathrm{H}_{8}\right]$-valine for quantification.

\section{Analysis of Apoptosis}

Cells were stained simultaneously with fluorescein isothiocyanate-conjugated Annexin $\mathrm{V}$ and propidium iodide (PI) (both from BD-Pharmingen, Heidelberg, Germany) as described. ${ }^{23}$

Further, formalin-fixed, paraffin-embedded tissue samples were stained for apoptotic cells by using the DeadEnd fluorometric terminal deoxynucleotidyl transferase dUTP nick-end labeling system (Promega, Mannheim, Germany). Intact nuclei were stained with DAPI by using Vectashield mounting medium with 4',6Diamidino-2-phenylindol (DAPI) (Vector Laboratories, Burlingame, CA).

\section{Proliferation, Colony Formation in Soft Agar, and Migration Assays}

Cell proliferation, colony formation in soft agar, and migration assays were performed as described. ${ }^{23}$

\section{Statistical Analysis}

$P$ values $<0.05$ were considered significant. Statistical analyses were performed by using SPSS version 10.0 (SPSS, Chicago, IL). Results are expressed as mean \pm $\mathrm{SD}$ (range) or percent. Comparison between groups was made by using the Student's unpaired $t$ test. Correlation between parameters was calculated with the Spearman test. Contingency table analysis and two-sided Fisher's exact tests were used to study the statistical association between clinicopathological and immunohistochemical variables.

\section{Results}

\section{FGFR2-IIIl Expression in Hepatocellular Carcinoma}

Recently, we have shown that FGFR2-IIlb is highly expressed in hepatocytes. ${ }^{21}$ Here, we studied its expression in HCC. Initially, we analyzed FGFR2-IIIb mRNA expression in three different $\mathrm{HCC}$ cell lines and $\mathrm{PHH}$ from three different donors by quantitative PCR. In contrast to PHH, FGFR2-IIIb mRNA expression was lost in all three HCC cell lines (Figure 1A).

To further address FGFR2-IIIb expression in HCC in vivo, we analyzed paired specimens obtained from two 

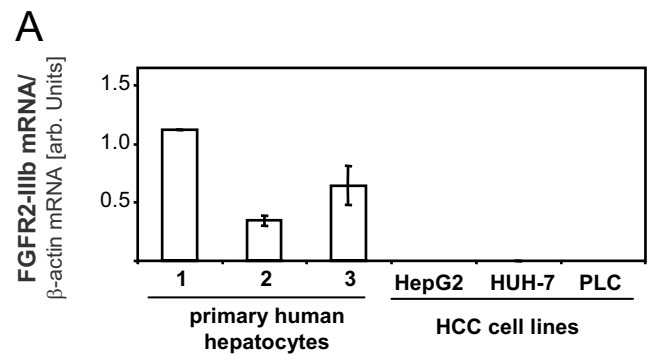

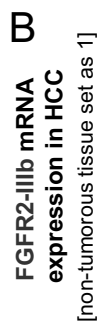

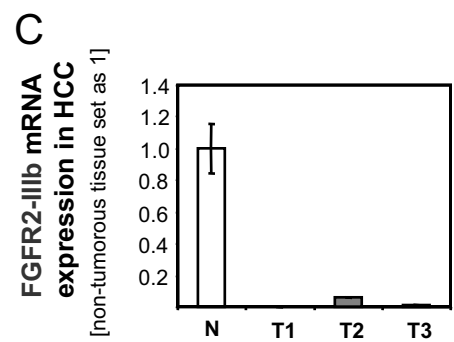

D

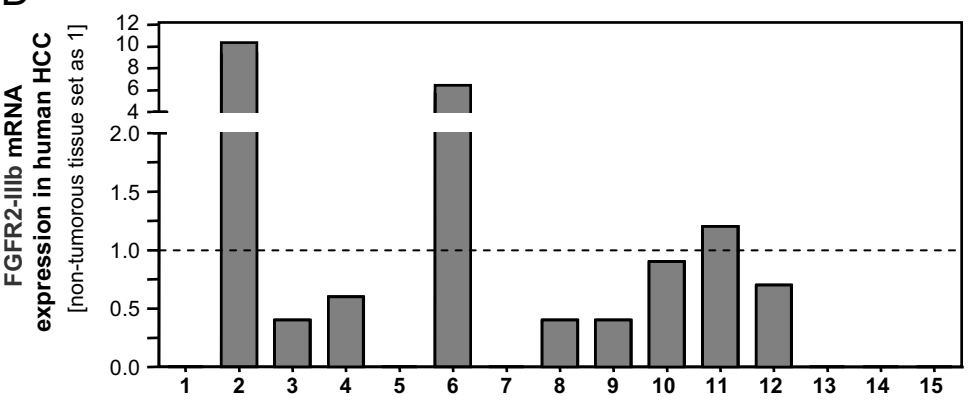

Figure 1. FGFR2-IIIb expression in HCC. FGFR2-IIIb mRNA expression was determined by using quantitative RT-PCR in (A) PHH and three HCC cell lines, two murine HCC models, (B) c- myc and (C) IgEGF transgenic animals, and (D) 15 human HCC samples and corresponding nontumorous liver tissue samples. E: Immunohistochemical staining for FGFR2-IIIb (left) and H\&E staining (right) of HCC and neighboring nontumorous (nt) liver tissue are shown. F: Proliferation rate (analyzed by immunohistochemical staining applying Ki-67 antibodies) in HCC tissues with different FGFR2-IIIb immunoreactivity is shown.

$E$

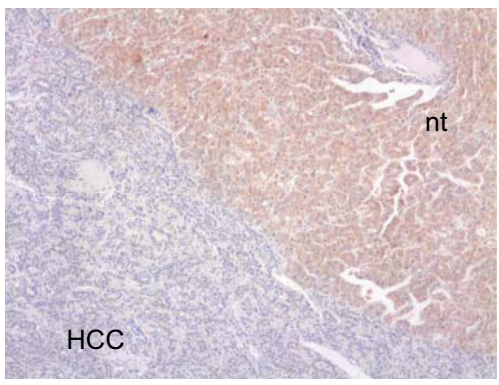

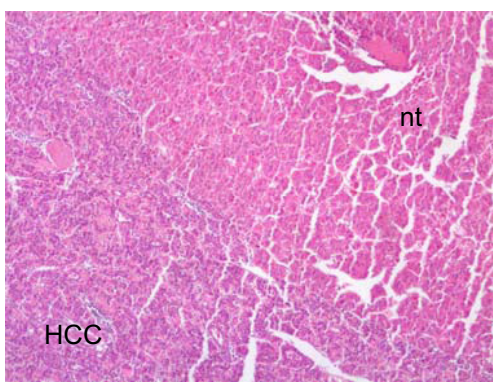

$\mathrm{F}$

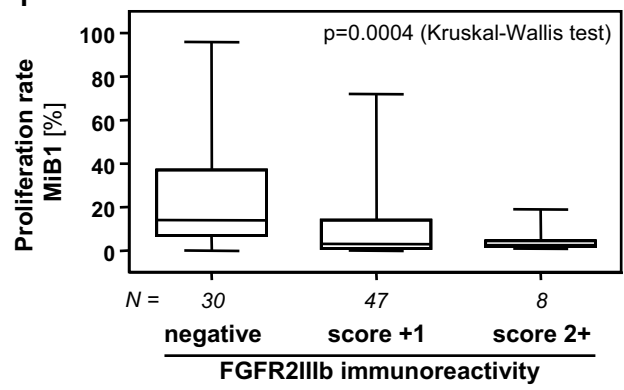

murine HCC models. ${ }^{26}$ HCCs isolated from c-myc and IgEGF transgenic animals exhibited lost or significantly down-regulated FGFR2-IIIb mRNA expression compared with surrounding non-neoplastic hepatic tissue (Figure 1, $B$ and $C$ ).

Next, we analyzed a panel of 15 paired specimens obtained from patients with HCC. From each patient with HCC, RNA was isolated from cancerous tissue and surrounding nontumorous liver tissue, and FGFR2-IIIb mRNA expression was measured by quantitative RT-PCR (Figure 1D). In 11 HCC specimens, FGFR2-IIlb mRNA expression was significantly reduced compared with matched nontumorous tissue (healthy liver [set as 1.0] versus HCC: mean of difference $0.65 \% \pm 0.13 \%$; $P<$ $0.0001)$, including six HCC tissue samples where no FGFR2-IIlb mRNA expression was detectable. In two patients (numbers 10 and 11), FGFR2-IIIb mRNA expression was not significantly different compared with nontumorous tissue, and only two HCC specimens (numbers 2 and 6) revealed increased FGFR2-IIIb mRNA expression levels compared with matched nontumorous tissue specimens.

To assess FGFR2-IIIb protein expression in HCC in situ, we performed immunohistochemical staining for FGFR2-IIlb by applying a newly generated polyclonal antibody that specifically recognizes the IIIb variant of the FGFR2 receptor.

Initially, we analyzed sections of tumorous tissue and neighboring non-neoplastic liver tissue of five patients with HCC. A representative immunohistochemical staining is presented in Figure 1E, revealing strong membranous immunosignals in hepatocytes in nontumorous tissue. In contrast, FGFR2-IIIb protein staining was reduced or even undetectable in HCC.

Next, we analyzed FGFR2-IIIb protein expression in a series of 85 HCCs and corresponding nontumorous tissue of the same patients $(n=81)$ by using tissue microarray technology. Investigation of FGFR2-IIlb protein expression was informative in all $\mathrm{HCC}$ and nontumorous tissue samples. The clinicopathological features and immunohistochemical results of the HCC tumor cohort are summarized in Table 1.

In 35.3\% (30 of 85) of the HCC, no FGFR2-IIIb immunosignal was detectable. In contrast, FGFR2-IIIb protein expression (immunoreactivity score $1+$ or $2+$ ) was found in all noncancerous tissue samples, and noteworthy, in $59.3 \%$ (48 of 81 ) of cases the FGFR2III staining signal was lower in $\mathrm{HCC}$ than in corresponding nontumorous liver tissue $(P=0.027)$. For descriptive data analysis, all relevant variables were compared with FGFR2III immu- 
A

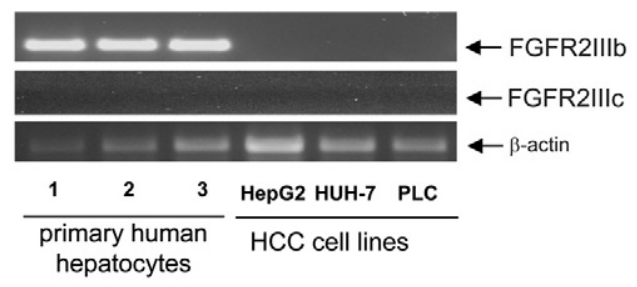

B

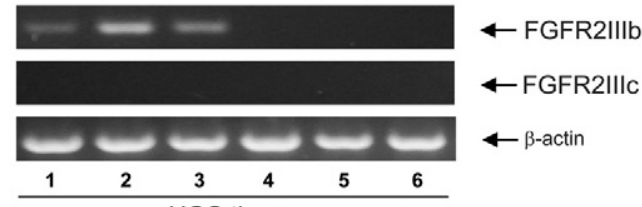

HCC tissues

C
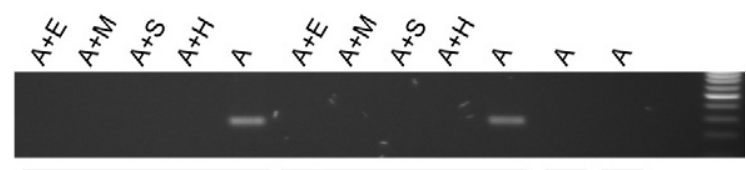
primary human hepatocytes PLC

$\mathrm{D}$

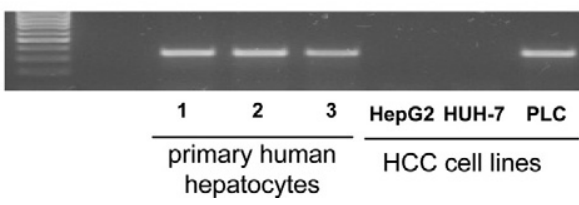

Figure 2. Analysis of FGFR2-IIIc expression and FGFR2-IIIb promotor methylation in HCC. RT-PCR analysis of FGFR2-IIIc and FGFR2-IIIb mRNA expression in primary human hepatocytes and three different HCC cell lines (A) and primary human HCC tissues of six different donors $(\mathbf{B})$ is shown. $\beta$-actin served as a control. C: Methylation-sensitive PCR analysis of the CpG island in the $5^{\prime}$-region of the FGFR2 gene is shown. PCR of DNA samples were digested with AfII (A, cutting outside the region analyzed) as a positive control, AfII plus MspI (A + M, cutting within the region analyzed, methylation-insensitive) as a negative control, and AfII plus SmaI $(A+S)$, HpaII $(\mathrm{A}+\mathrm{H})$, or EclVI $(\mathrm{A}+\mathrm{E})$ (all three cutting within the region analyzed and methylation-sensitive). D: Amplification of a 34-bp fragment containing exon 8 of the FGFR2 gene is shown.

nohistochemistry (IHC) (Table 1). Loss of FGFR2III expression was significantly associated with higher tumor stage $(P=0.016)$ and vascular invasion $(P=0.030)$. Furthermore, FGFR2-IIlb negative HCC had a significant higher proliferation rate (MiB-1 Index) compared with FGFR2IIlb positive HCCs ( $P<0.0004$; Figure 1F). No correlation could be found with FGFR2-IIIb protein expression and age, gender, histological grade, size, or etiology of the underlying liver disease.

\section{Molecular Mechanisms of FGFR2-IIIb Down-regulation in HCC}

Decreased expression of FGFR2-IIIb in carcinoma cells was found to be associated with increased expression of Bek (FGFR2-IIIc). ${ }^{30,31}$ To analyze whether the decrease in FGFR2-IIIb mRNA in HCC is accompanied by an increase in FGFR2-IIIc mRNA, we analyzed the expression of this second major splice variant of the FGFR2 gene in $\mathrm{HCC}$ cell lines by PCR. Neither in $\mathrm{PHH}$ nor in any of the three HCC cell lines was FGFR2-IIlc detected (Figure $2 \mathrm{~A})$. Further, neither HCC tissues with $(n=3)$ nor HCC tissues without $(n=3)$ detectable FGFR2-IIIb expression, respectively, revealed FGFR2-IIIC expression (Figure
2B). Together, these data indicate that the decrease in FGFR2-IIIb mRNA in HCC was not associated with an increase in FGFR2-IIIc mRNA.

The $5^{\prime}$-region of the FGFR2 gene has been characterized and shown to contain a CpG island, and hypermethylation of this normally unmethylated CpG island correlated with loss of transcription in a subset of human bladder cancer cell lines and tissues. ${ }^{10}$ To analyze whether promotor methylation is also causing down-regulation of FGFR2-IIIb in HCC, we treated HCC cells with the DNA methyltransferase inhibitor 5-Aza-2'-deoxycytidine. FGFR2-IIlb mRNA expression was not affected by 5-Aza-2'-deoxycytidine (data not shown), whereas this treatment clearly reactivated expression of MTAP (data not shown), a gene that we have recently shown to be negatively regulated in HCC via promoter methylation. ${ }^{27}$

Furthermore, a PCR-based assay was used to analyze the methylation status of the CpG island in the $5^{\prime}$-region of the FGFR2 gene as described. ${ }^{10}$ Double digestion using a restriction enzyme with flanking cut (AfIII) and methylation-sensitive enzymes (Smal, Hpall, or Eagl) was followed by PCR amplification of the promotor region harboring the $\mathrm{CpG}$ island. $\mathrm{PHH}$ as well as PLC cells are unmethylated at the sites tested within this region (Figure 2C). Notably, in HepG2 and Huh7 cells no PCR product could be amplified. Moreover, also a further fragment of the FGFR2 gene containing exon 8 could not be amplified, whereas PCR analysis of $\mathrm{PHH}$ as well as PLC cells revealed a fragment of the expected size (Figure 2D). These findings suggested that gross genomic alterations frequently described at chromosomal region $10 \mathrm{q}$ (where the FGFR2 gene is located) may account for the loss of FGFR2 expression in a subset of HCC cells. ${ }^{32,33}$

\section{Re-expression of FGFR2-IIIb in HCC Cells}

To gain insight into the functional role of reduced FGFR2IIlb in HCC, FGFR2-IIlb was re-induced in the HCC cell line HepG2 by stable transfection with a FGFR2-IIlb expression vector containing the full-length FGFR2-IIIb cDNA under the control of the cytomegalovirus promotor (clone 1, 2, and 3). The vector without an insert was used as a control (mock). Quantitative RT-PCR analysis revealed a strong induction of FGFR2-IIIb mRNA expression in the cell clones, whereas no (change of) FGFR2IIIb expression was seen in mock-transfected cell clones (Figure 3A). Up-regulation of FGFR2-IIlb expression in the cell clones was confirmed on protein level by using Western blot (Figure 3B) and lead to similar levels as found in $\mathrm{PHH}$ (data not shown). The stable FGFR2-IIIbexpressing cells were similar in morphology to mock and nontransfected parental cells (data not shown).

Since overexpression of genes may lead to nonspecific effects on (overall functions of) cells, we determined incorporation of deuterium labeled valine $\left(\left[{ }^{2} \mathrm{H}_{8}\right]\right.$-valine) into proteins of FGFR2-IIIb-expressing and control cells, and we did not detect significant differences (Figure 3C). Furthermore, analysis of cell culture supernatant revealed similar levels of albumin and cholinesterase in FGFR2Illb-expressing cell clones and control cells (data not shown). These findings indicate that FGFR2-IIIb overex- 
A

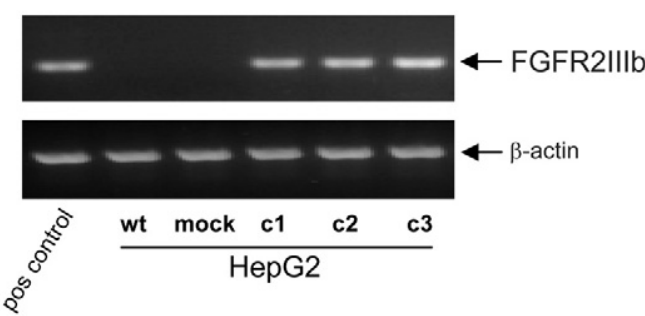

B

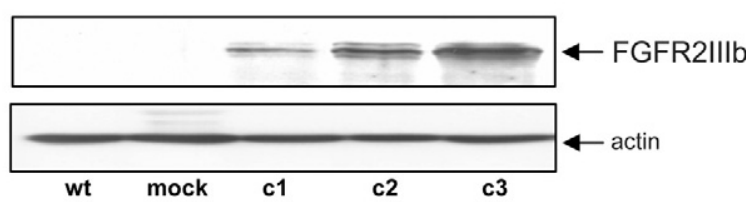

C

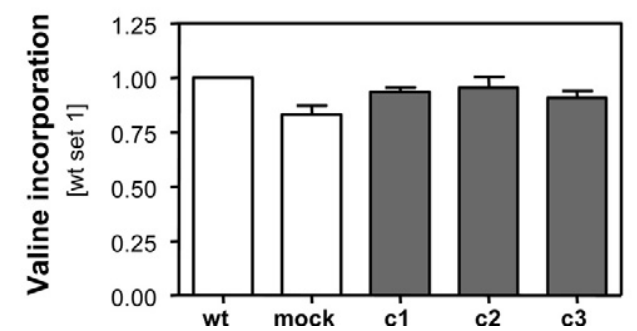

Figure 3. Re-expression of FGFR2-IIIb in HCC cells. Analysis of FGFR2IIIb mRNA (A) and protein expression (B) in stable transfected HepG2 cell clones (c1-c3), mock transfected controls (mock), and nontransfected cells (wt) by quantitative RT-PCR and Western blotting is shown. C: Overall, protein synthesis was analyzed by determining $\left[{ }^{2} \mathrm{H}_{8}\right]$-valine protein incorporation.

pression does not (nonspecifically) affect overall protein synthesis or general cellular functions of FGFR2-IIIb-expressing cell clones.

\section{Functional Changes after FGFR2-IIIb Re-expression in HCC Cells In Vitro}

To further characterize the role of FGFR2-IIIb in HCC cells, we performed functional in vitro assays with FGFR2IIlb-expressing cell clones in comparison with mocktransfected cells and the parental cell line. Proliferation was significantly impaired in FGFR2-IIlb re-expressing cell clones (Figure 4A)

To determine whether FGFR2-IIIb modulates anchorage-independent growth of $\mathrm{HCC}$, we analyzed the colony formation of cells in standard soft agar assays. HCC cells stably expressing FGFR2-IIlb showed diminished growth, whereas mock or nontransfected cells formed numerous colonies in soft agar (Figure 4B).

In addition to proliferation, growth of tumors is determined by apoptosis. Therefore, we analyzed whether FGFR2-IIIb expression affects apoptosis in a recently described in vitro model of lipoapoptosis. ${ }^{25}$ Treatment with palmitate $(0.1 \mu \mathrm{mol} / \mathrm{L} ; 24$ hours $)$ induced apoptosis to a similar extent in nontransfected HCC (25.0 $\pm 4.2 \%)$ and mock transfected cells $(21.9 \pm 2.4 \%)$. In contrast, FGFR2-IIlb-expressing clones exhibited a significantly higher number of apoptotic cells (clone 1: $35.4 \pm 1.5 \%$, clone 2: $41.2 \pm 1.1 \%$, and clone $3: 51.2 \pm 0.4 \% ; P<0.05$ as compared with both nontransfected or mock transfected controls) (Figure 4C).
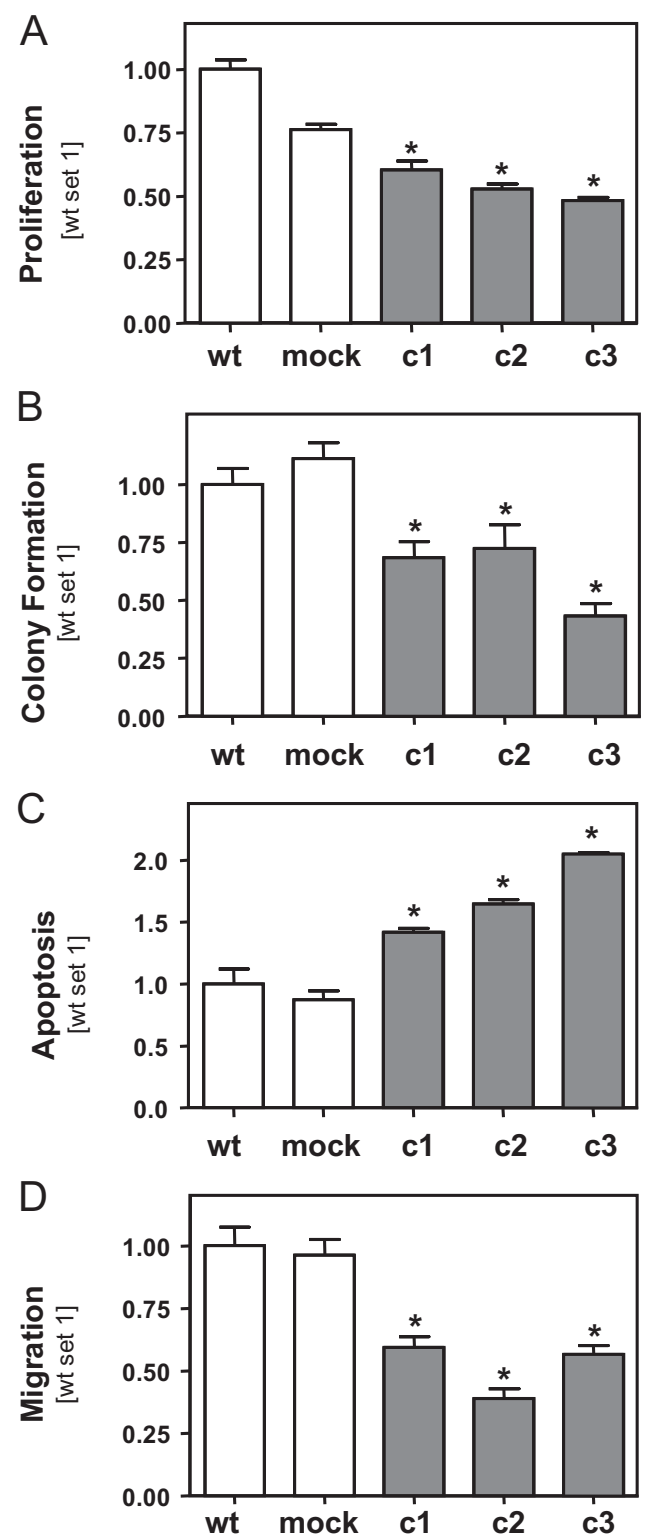

Figure 4. Functional analysis of FGFR2-IIIb re-expressing HCC cells in vitro. Proliferation (A), attachment independent growth (analyzed by soft agar colony formation assays, B), apoptosis (analyzed by fluorescence activated cell sorting (FACS) analysis, C), and migratory potential (assessed by Boyden Chamber assays, D) of HepG2 cell clones stably expressing FGFR2-IIIb (c1-3), mock transfected controls (mock), and nontransfected (wt) controls are shown. ${ }^{*} P<0.05$.

Next, we analyzed whether FGFR2-IIIb expression affects the migratory potential of HCC cells in vitro. In Boyden Chamber assays, FGFR2-IIIb-expressing clones revealed a significantly reduced migration compared with mock or nontransfected cells (Figure 4D). These data indicate that rescue of FGFR2-IIIb expression in HCC cells inhibits tumorigenicity of HCC cells in vitro.

\section{Effect of KGF and an Inhibitor of Tyrosine Kinase Activity on Tumorigenicity of FGFR2-IIIb} Re-expressing HCC Cells

KGF (FGF7) is signaling exclusively via FGFR2-IIlb, and we have shown that KGF is de novo expressed in chronic 


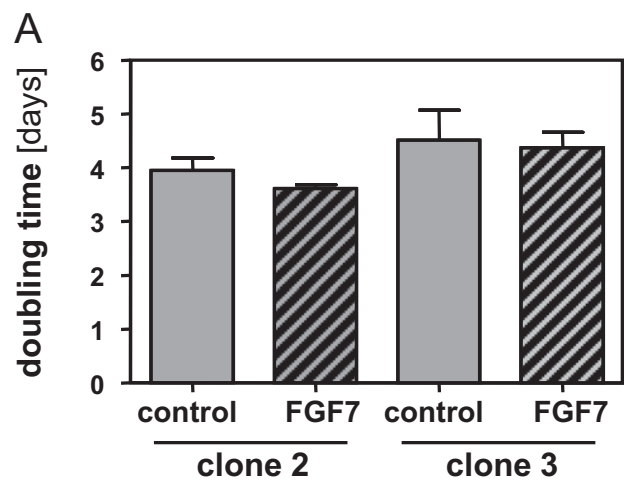

B

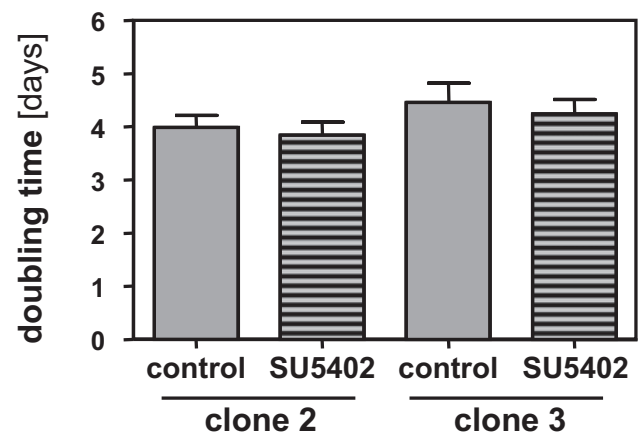

Figure 5. Effect of KGF and SU5402, an inhibitor of tyrosine kinase activity, on proliferation of FGFR2-IIIb re-expressing HCC cells. Proliferation was analyzed in HepG2 cell clones stably expressing FGFR2-IIIb (clone 2 and clone 3) pretreated or not with $\mathrm{KGF}(20 \mathrm{ng} / \mathrm{ml}, \mathbf{A}$ ) or FGFR tyrosine kinase inhibitor (SU5402; $30 \mu \mathrm{mol} / \mathrm{L}, \mathbf{B}$ ).

liver disease. ${ }^{21}$ Furthermore, we found increased KGF expression in human HCC tissue (data not shown). Therefore, we tested the effect of KGF on FGFR2-IIIb re-expressing clones as well as mock transfected and nontransfected controls, respectively. KGF treatment affected proliferation in neither FGFR2-IIlb-expressing cell clones nor control cells (Figure 5A).

It has been previously shown in other tumors that tyrosine phosphorylation of FGFR2-IIIb is not required for growth inhibition of tumor cells. ${ }^{34}$ To analyze whether this is also true in $\mathrm{HCC}$, we evaluated the growth inhibitory activity of FGFR2-IIlb-expressing cell clones in the presence of an inhibitor of FGFR tyrosine kinase activity.
SU5402 is an ATP mimetic known to inhibit FGFR1 and FGFR2 phosphorylation by binding to the ATP-binding site. As expected based on the considerable sequence and structure similarity of the catalytic domains of FGFRs and recently confirmed by Bernard-Pierrot et $\mathrm{al}^{34}$ SU5402 also inhibits FGFR2-IIlb phosphorylation. However, the inhibition of proliferation induced by expression of FGFR2-IIlb in HCC cells was not affected by SU5402 (Figure 5B). These results reinforce the hypothesis that growth inhibitory properties of FGFR2-IIIb are independent of the kinase activity of this receptor also in HCC.

\section{Tumorigenicity of FGFR2-IIIb Re-expressing HCC Cells In Vivo}

To test the effect of FGFR2-IIIb on tumor growth in vivo HCC cells stably expressing FGFR2-IIlb were injected subcutaneously into nude mice. All 10 animals in each group developed tumors between day 7 and day 21, but tumors derived from FGFR2-IIlb overexpressing HCC cell clones were significantly smaller than tumors from the mock or wild-type control group (Figure 6A).

Analysis for apoptotic cells by using the terminal deoxynucleotidyl transferase dUTP nick-end labeling system showed hardly any apoptotic cells in mock-transfected HCC derived tumors, whereas the FGFR2-IIIb overexpressing tumors displayed large apoptotic areas (Figure 6B). In summary, data obtained in nude mice indicate that reduced FGFR2-IIIb expression in HCC cells induces tumorigenicity of HCC cells.

\section{Discussion}

Here we show that FGFR2-IIIb is down-regulated or lost in HCC cells compared with primary human hepatocytes, and FGFR2-IIIb is down-regulated or lost in murine HCC and a subset of human HCC as compared with nonneoplastic tissue. To analyze whether FGFR2-IIlb may simply be a differentiation marker, which is lost in (the most aggressive) tumors, or may play an active role in maintaining epithelial cells in a less aggressive phenotype, we re-expressed FGFR2-IIIb in a HCC cell line,
A

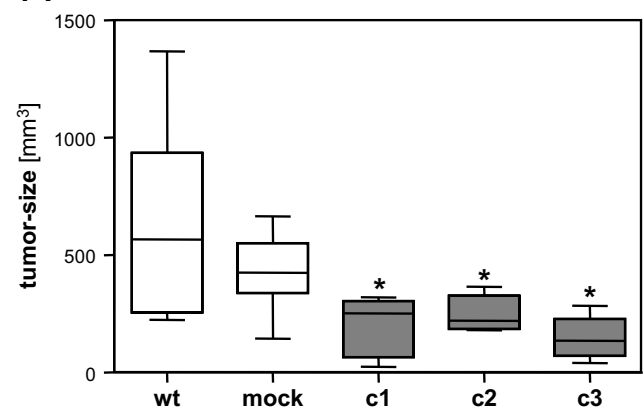

B

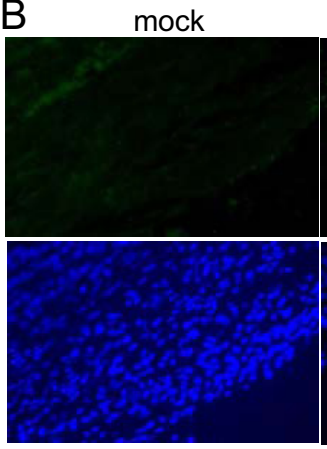

clone 1

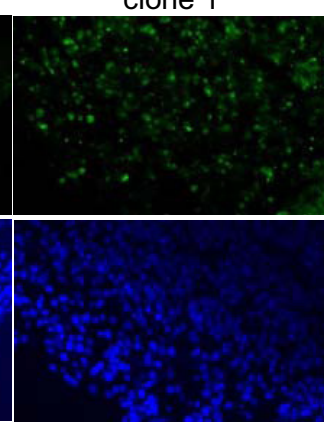

clone 3

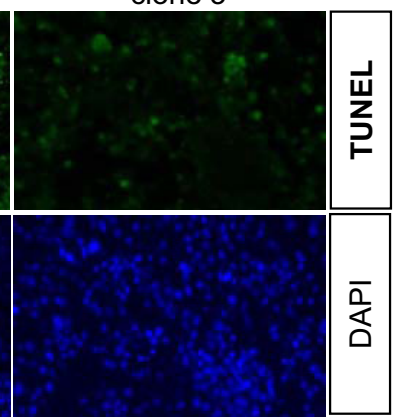

Figure 6. Tumorigenicity of FGFR2-IIIb re-expressing HCC cells in vivo. A: Tumor size 21 days after implantation of $1 \times 10^{6}$ HepG 2 cells stably transfected with a FGFR2-IIIb-expression plasmid (c1-3) and mock transfected (mock) and nontransfected control cells into nude mice $(n=10 /$ group). * $P<0.05$ compared with both wt and mock. B: Analysis for apoptotic cells by using terminal deoxynucleotidyl transferase dUTP nick-end labeling staining. DAPI staining of the same section was applied to visualize cell nuclei. 
which lacks endogenous FGFR2-IIlb expression. Restoration of FGFR2-IIlb expression markedly inhibited migration and growth both in vitro and in vivo, consequently reducing tumorigenicity of HCC cells. Coincident with suppression of growth and tumorigenicity was an increase in apoptosis on FGFR2-IIIb re-expression. Additionally, we found that loss of FGFR2-IIllb expression is associated with higher tumor stage, vascular invasion, and cell proliferation in patients with HCC. Thus, this work provides direct evidence that FGFR2-IIIb inhibits tumorigenicity of $\mathrm{HCC}$ cells in vitro and in vivo.

The FGFR2-IIIb signaling pathway can lead to mitogenesis, as is the case for basal cells of the skin or bladder wound healing, ${ }^{35,36}$ and progression of tumors, as in poorly differentiated carcinomas of the stomach. ${ }^{37,38}$ Alternatively, the same receptor may be implicated in the control of cell differentiation, as in the suprabasal cells of the skin $^{39}$ and in the maintenance of certain carcinomas in less aggressive forms as in this study and others. ${ }^{12}$ Previously, we have shown that FGFR2-IIIb plays a critical role in liver regeneration and homeostasis. ${ }^{22}$ Our data indicate that the growth limitation of FGFR2-IIIb re-expressing HCC cells is likely through maintenance of homeostasis or the balance among proliferation, apoptosis, and differentiation.

The inhibitory properties of FGFR2-IIIb and the frequent loss of or decrease in FGFR2-IIlb expression in $\mathrm{HCC}$ tissue and most cell lines suggest that the inactivation of FGFR2-IIIb is a critical step in the development and progression of HCC. Several mechanisms may be responsible for FGFR2 gene silencing.

Several splice variants are generated from the FGFR2, and decreased expression of FGFR2-IIIb in carcinoma cells has been reported to be associated with increased expression of Bek (FGFR2-IIIC). ${ }^{30,31}$ In fact, regardless of IIIb exon expression, forms containing the IIlc exon were undetectable in HCC indicating that FGFR2 gene expression is repressed.

The 5'-region of the FGFR2-gene contains a CpG island, suggesting a possible regulation by hypermethylation. And indeed, it has been shown that epigenetic modifications caused silencing of FGFR2-IIIb expression in some tumors as bladder or gastric cancer. ${ }^{10,40}$ However, treatment with the DNA methyltransferase inhibitor 5-Aza-2'-deoxycytidine did not restore FGFR2-IIIb expression, and methylation-specific PCR analysis indicates that promoter methylation is not the cause for the down-regulation of FGFR2-IIIb in HCC.

Interestingly, defined genomic regions of the FGFR2 gene could not be amplified in two of the HCC cell lines analyzed. The FGFR2 gene has been mapped to chromosome region 10q25.3-10q26, ${ }^{32}$ and HCC display gross genomic alterations, including chromosomal instability at chromosomal region $10 \mathrm{q} .^{33}$ Herewith, and although not systematically analyzed, it may be suggested that-at least in a subset of HCC cells-genomic alterations are responsible for the loss of FGFR2-IIIb expression in HCC. However, further mechanisms as altered chromatin structure in the FGFR2 region or loss of transactivators of the FGFR2 gene have to be considered, and further studies are required to elucidate the molecular mechanisms of FGFR2-IIIb down-regulation in a subset of HCC.

Further, so far, we can only speculate on the molecular mechanisms how FGFR2-IIIb exhibits its antitumorigenicity effects in HCC. Interestingly, tyrosine phosphorylation of FGFR2-IIIb is probably not required for tumor suppressive activity in HCC, similarly as previously shown for bladder cancer cells in vitro. ${ }^{34}$ Further, in a mouse model of prostate cancer, growth inhibition was observed in the absence of receptor activation. ${ }^{41}$ Together these data suggest that the nonphosphotyrosine-containing region within the C-terminal part of FGFR2-IIl b plays the key role in the FGFR2-IIIb-induced inhibitory signal in some tumor entities including HCC.

In line with this hypothesis, KGF/FGF7, a specific FGFR2-IIIb ligand, had no effect on the growth of FGFR2IIlb-expressing HCC cell clones. In contrast, KGF has been shown to induce proliferation of hepatocytes in vitro and in vivo ${ }^{42}$ and to decrease apoptosis in hepatocytes after treatment with actinomycin and tumor necrosis factor in vitro or with lipopolysaccharide and D-galactosamine in vivo. ${ }^{43}$ Together these findings suggest that FGFR2-IIlb signaling is critical for the maintenance of liver homeostasis, with so far unknown mechanisms affecting growth and invasiveness of HCC cells.

Thus, the monitoring of FGFR2-IIIb expression may be used as a marker for HCC progression, and identification of the molecular mechanisms responsible for the antitumoral effects of FGFR2-IIIb may lead to novel therapeutic targets to inhibit the progression of this highly aggressive tumor.

\section{Acknowledgments}

We thank Kornelia Elser and Nadine Nuernberger for excellent technical assistance.

\section{References}

1. Itoh N, Ornitz DM: Evolution of the Fgf and Fgfr gene families. Trends Genet 2004, 20:563-569

2. Ornitz DM, Itoh N: Fibroblast growth factors. Genome Biol 2001 2:reviews 3005.1-3005.12

3. Ingersoll RG, Paznekas WA, Tran AK, Scott AF, Jiang G, Jabs EW: Fibroblast growth factor receptor 2 (FGFR2): genomic sequence and variations. Cytogenet Cell Genet 2001, 94:121-126

4. McKeehan WL, Wang F, Kan M: The heparan sulfate-fibroblast growth factor family: diversity of structure and function. Prog Nucleic Acid Res Mol Biol 1998, 59:135-176

5. Xiao S, Nalabolu SR, Aster JC, Ma J, Abruzzo L, Jaffe ES, Stone R, Weissman SM, Hudson TJ, Fletcher JA: FGFR1 is fused with a novel zinc-finger gene, ZNF198, in the $\mathrm{t}(8 ; 13)$ leukaemia/lymphoma syndrome. Nat Genet 1998, 18:84-87

6. Billerey C, Chopin D, Aubriot-Lorton MH, Ricol D, Gil Diez dM, Van Rhijn B, Bralet MP, Lefrere-Belda MA, Lahaye JB, Abbou CC, Bonaventure J, Zafrani ES, van der KT, Thiery JP, Radvanyi F: Frequent FGFR3 mutations in papillary non-invasive bladder (pTa) tumors. Am J Pathol 2001, 158:1955-1959

7. Eswarakumar VP, Lax I, Schlessinger J: Cellular signaling by fibroblast growth factor receptors. Cytokine Growth Factor Rev 2005 , 16:139-149

8. Yasumoto H, Matsubara A, Mutaguchi K, Usui T, McKeehan WL: Restoration of fibroblast growth factor receptor2 suppresses growth 
and tumorigenicity of malignant human prostate carcinoma PC-3 cells. Prostate 2004, 61:236-242

9. Naimi B, Latil A, Fournier G, Mangin P, Cussenot O, Berthon $P$ : Down-regulation of (IIIb) and (IIIC) isoforms of fibroblast growth factor receptor 2 (FGFR2) is associated with malignant progression in human prostate. Prostate 2002, 52:245-252

10. Ricol D, Cappellen D, El Marjou A, Gil-Diez-de-Medina S, Girault JM, Yoshida T, Ferry G, Tucker G, Poupon MF, Chopin D, Thiery JP Radvanyi F: Tumour suppressive properties of fibroblast growth factor receptor 2-IIIb in human bladder cancer. Oncogene 1999, 18:7234-7243

11. Gartside MG, Chen H, Ibrahimi OA, Byron SA, Curtis AV, Wellens CL, Bengston A, Yudt LM, Eliseenkova AV, Ma J, Curtin JA, Hyder P Harper UL, Riedesel E, Mann GJ, Trent JM, Bastian BC, Meltzer PS, Mohammadi M, Pollock PM: Loss-of-function fibroblast growth factor receptor-2 mutations in melanoma. Mol Cancer Res 2009, 7:41-54

12. Finch PW, Rubin JS: Keratinocyte growth factor expression and activity in cancer: implications for use in patients with solid tumors. J Natl Cancer Inst 2006, 98:812-824

13. Pollock PM, Gartside MG, Dejeza LC, Powell MA, Mallon MA, Davies H, Mohammadi M, Futreal PA, Stratton MR, Trent JM, Goodfellow PJ: Frequent activating FGFR2 mutations in endometrial carcinomas parallel germline mutations associated with craniosynostosis and skeletal dysplasia syndromes. Oncogene 2007, 26:7158-7162

14. Dutt A, Salvesen HB, Chen TH, Ramos AH, Onofrio RC, Hatton C Nicoletti R, Winckler W, Grewal R, Hanna M, Wyhs N, Ziaugra L, Richter DJ, Trovik J, Engelsen IB, Stefansson IM, Fennell T, Cibulskis K, Zody MC, Akslen LA, Gabriel S, Wong KK, Sellers WR, Meyerson $\mathrm{M}$, Greulich H: Drug-sensitive FGFR2 mutations in endometrial carcinoma. Proc Natl Acad Sci USA 2008, 105:8713-8717

15. El Serag HB, Rudolph KL: Hepatocellular carcinoma: epidemiology and molecular carcinogenesis. Gastroenterology 2007, 132:2557-2576

16. Farazi PA, DePinho RA: Hepatocellular carcinoma pathogenesis: from genes to environment. Nat Rev Cancer 2006, 6:674-687

17. Bruix J, Boix L, Sala M, Llovet JM: Focus on hepatocellular carcinoma. Cancer Cell 2004, 5:215-219

18. El Serag HB, Marrero JA, Rudolph L, Reddy KR: Diagnosis and treatment of hepatocellular carcinoma. Gastroenterology 2008 , 134:1752-1763

19. Bataller R, Brenner DA: Liver fibrosis. J Clin Invest 2005, 115:209-218

20. Friedman SL: Mechanisms of hepatic fibrogenesis. Gastroenterology 2008, 134:1655-1669

21. Steiling $H$, Muhlbauer M, Bataille $F$, Scholmerich J, Werner $S$, Hellerbrand C: Activated hepatic stellate cells express keratinocyte growth factor in chronic liver disease. Am J Pathol 2004, 165:1233-1241

22. Steiling H, Wustefeld T, Bugnon P, Brauchle M, Fassler R, Teupser D, Thiery J, Gordon JI, Trautwein C, Werner S: Fibroblast growth factor receptor signaling is crucial for liver homeostasis and regeneration. Oncogene 2003, 22:4380-4388

23. Hellerbrand C, Amann T, Schlegel J, Wild P, Bataille F, Spruss T, Hartmann A, Bosserhoff AK: The novel gene MIA2 acts as a tumour suppressor in hepatocellular carcinoma. Gut 2008, 57:243-25

24. Dell KR, Williams LT: A novel form of fibroblast growth factor receptor 2: alternative splicing of the third immunoglobulin-like domain confers ligand binding specificity. J Biol Chem 1992, 267:21225-21229

25. Malhi H, Bronk SF, Werneburg NW, Gores GJ: Free fatty acids induce JNK-dependent hepatocyte lipoapoptosis. J Biol Chem 2006, 281:12093-12101

26. Liedtke C, Zschemisch NH, Cohrs A, Roskams T, Borlak J, Manns MP, Trautwein C: Silencing of caspase-8 in murine hepatocellular carcinomas is mediated via methylation of an essential promoter element. Gastroenterology 2005, 129:1602-1615

27. Hellerbrand C, Muhlbauer M, Wallner S, Schuierer M, Behrmann I, Bataille F, Weiss T, Scholmerich J, Bosserhoff AK: Promoter-hypermethylation is causing functional relevant downregulation of methyl- thioadenosine phosphorylase (MTAP) expression in hepatocellular carcinoma. Carcinogenesis 2006, 27:64-72

28. Sugitani H, Wachi H, Tajima S, Seyama Y: Nitric oxide stimulates elastin expression in chick aortic smooth muscle cells. Biol Pharm Bull 2001, 24:461-464

29. Kaspar H, Dettmer K, Gronwald W, Oefner PJ: Advances in amino acid analysis. Anal Bioanal Chem 2009, 393:445-452

30. Yan G, Fukabori Y, McBride G, Nikolaropolous S, McKeehan WL: Exon switching and activation of stromal and embryonic fibroblast growth factor (FGF)-FGF receptor genes in prostate epithelial cells accompany stromal independence and malignancy. Mol Cell Biol 1993, 13:4513-4522

31. Savagner P, Valles AM, Jouanneau J, Yamada KM, Thiery JP: Alternative splicing in fibroblast growth factor receptor 2 is associated with induced epithelial-mesenchymal transition in rat bladder carcinoma cells. Mol Biol Cell 1994, 5:851-862

32. Mattei MG, Moreau A, Gesnel MC, Houssaint E, Breathnach R: Assignment by in situ hybridization of a fibroblast growth factor receptor gene to human chromosome band 10q26. Hum Genet 1991, 87:84-86

33. Herath $\mathrm{NI}$, Leggett BA, MacDonald GA: Review of genetic and epigenetic alterations in hepatocarcinogenesis. J Gastroenterol Hepato 2006, 21:15-21

34. Bernard-Pierrot I, Ricol D, Cassidy A, Graham A, Elvin P, Caillault A Lair S, Broet P, Thiery JP, Radvanyi F: Inhibition of human bladder tumour cell growth by fibroblast growth factor receptor $2 \mathrm{~b}$ is independent of its kinase activity: involvement of the carboxy-terminal region of the receptor. Oncogene 2004, 23:9201-9211

35. Werner S, Breeden M, Hubner G, Greenhalgh DG, Longaker MT Induction of keratinocyte growth factor expression is reduced and delayed during wound healing in the genetically diabetic mouse. J Invest Dermatol 1994, 103:469-473

36. Baskin LS, Sutherland RS, Thomson AA, Nguyen HT, Morgan DM, Hayward SW, Hom YK, DiSandro M, Cunha GR: Growth factors in bladder wound healing. J Urol 1997, 157:2388-2395

37. Ishii $H$, Hattori $Y$, Itoh $H$, Kishi $T$, Yoshida T, Sakamoto $H$, Oh $H$, Yoshida S, Sugimura T, Terada M: Preferential expression of the third immunoglobulin-like domain of K-sam product provides keratinocyte growth factor-dependent growth in carcinoma cell lines. Cancer Res 1994, 54:518-522

38. Itoh H, Hattori $Y$, Sakamoto H, Ishii H, Kishi T, Sasaki H, Yoshida T, Koono M, Sugimura T, Terada M: Preferential alternative splicing in cancer generates a K-sam messenger RNA with higher transforming activity. Cancer Res 1994, 54:3237-3241

39. Werner S, Weinberg W, Liao X, Peters KG, Blessing M, Yuspa SH, Weiner RL, Williams LT: Targeted expression of a dominant-negative FGF receptor mutant in the epidermis of transgenic mice reveals a role of FGF in keratinocyte organization and differentiation. EMBO $J$ 1993, 12:2635-2643

40. Park S, Kim JH, Jang JH: Aberrant hypermethylation of the FGFR2 gene in human gastric cancer cell lines. Biochem Biophys Res Commun 2007, 357:1011-1015

41. Freeman KW, Gangula RD, Welm BE, Ozen M, Foster BA, Rosen JM, Ittmann M, Greenberg NM, Spencer DM: Conditional activation of fibroblast growth factor receptor (FGFR) 1, but not FGFR2, in prostate cancer cells leads to increased osteopontin induction, extracellular signal-regulated kinase activation, and in vivo proliferation. Cancer Res 2003, 63:6237-6243

42. Housley RM, Morris CF, Boyle W, Ring B, Biltz R, Tarpley JE, Aukerman SL, Devine PL, Whitehead RH, Pierce GF: Keratinocyte growth factor induces proliferation of hepatocytes and epithelial cells throughout the rat gastrointestinal tract. J Clin Invest 1994, 94:1764-1777

43. Senaldi G, Shaklee CL, Simon B, Rowan CG, Lacey DL, Hartung T: Keratinocyte growth factor protects murine hepatocytes from tumor necrosis factor-induced apoptosis in vivo and in vitro. Hepatology $1998,27: 1584-1591$ 